\title{
You Sluice and hai Modification in Chinese
}

\author{
Ting-Chi Wei \\ National Kaohsiung Normal University
}

\begin{abstract}
This paper argues that you 'have' sluice is a variant of pseudosluicing, akin to shi 'be' sluice in Chinese. You sluice can be analyzed as a base-generated structure [pro you 'have' wh-phrase], consisting of a subject pro, a verb you 'have', and a wh-phrase, having nothing to do with movement and deletion. In this simple clause, the pro can either refer to a nominal antecedent or an event antecedent; you 'have' mainly denotes possessive or existential readings as well as extended attributive uses. This analysis further reveals how circum-phrase chule ... yiwei 'besides' semantically and syntactically interacts with hai 'still' in you sluice to express else modification in English sluicing derived by movement and deletion.
\end{abstract}

\section{Keywords}

hai, else, possessive, existential, sluicing, pseudosluicing

Studies in Chinese Linguistics, Volume 38, Number 1, 2017, 1-17 DOI: 10.1515/scl-2017-0001 (C2017 by T.T. Ng Chinese Language Research Centre, Institute of Chinese Studies, The Chinese University of Hong Kong 


\section{Introduction}

Merchant (2001:36-7) has proposed a sort of English sluicing involving else modification as given in (1).

(1) a. She called Ben an idiot, but I don't know who else [she ealled an idiot].

b. Abby speaks Greek, but I don't remember what other languages [Abby speaks].

He claims that the sluice can be analyzed by Focus condition on IP-ellipsis. ${ }^{1}$ The "sluice" in (1a) is defined as a structure containing the focus element Ben in the argument position of the first conjunct and the focused wh-nominal who else in the argument position of the second conjunct. These two focused elements can be analyzed as variables as in (2), contributing to the satisfaction of the mutual entailment, as illustrated in (3). Thus, the IP in the second conjunct is e-GIVEN and is eligible to be elided. Similar analysis can be applied to (1b).

(2) She called Ben an idiot, but I don't know who else [she called $x$ an idiot]. ${ }^{2}$

(3) a. $\mathrm{IP}_{\mathrm{A}}{ }^{\prime}=\exists \mathrm{x}$. she called $\mathrm{x}$ an idiot, $\mathrm{F}-\mathrm{clo}\left(\mathrm{IP}_{\mathrm{E}}\right)=\exists \mathrm{x}$. she called $\mathrm{x}$ an idiot.

b. $\mathrm{IP}_{\mathrm{E}}{ }^{\prime}=\exists x$. she called $\mathrm{x}$ an idiot, $\mathrm{F}-\operatorname{clo}\left(\mathrm{IP}_{\mathrm{A}}\right)=\exists \mathrm{x}$.she called $\mathrm{x}$ an idiot.

We may wonder whether this type of sluice can be found in wh-in-situ languages, such as Chinese. As can be seen in (4), its counterpart in Chinese is prohibited. When the $w h$-words containing the modifier qita 'other' appears, the sentence becomes ungrammatical, in contrast to the related structure commonly recognized as a sluicing in (5). The ungrammaticality of (4) seems to imply that Chinese has no counterpart of "else" modification in English sluicing.

(4) *Ta jian-dao le Lisi, dan wo bu zhidao (shi) qita shenme ren he see-arrive LE Lisi, but I not know be other what person [ta jian-dao le].

he see-arrive ASP

'(lit.) He saw Lisi, but I don't know who else/what other person (he saw).'

(5) Ta jian-dao le yi-ge ren, dan wo bu zhidao shishei/(shi)

he see-arrive LE one-CL person but I not know be who be

shenme ren.

what person

'He saw someone, but I don't know who/what person.'

1 The Focus condition on ellipsis (Merchant 2001:26) is formulated in (i). The e here stands for ellipsis. Whether a constituent is e-GIVEN depends on its antecedent. The notion of e-GIVENness is further defined as in (ii).

(i) An IP $\alpha$ can be deleted only if $\alpha$ is e-GIVEN.

(ii) e-GIVENness

An expression $\mathrm{E}$ counts as e-GIVEN if $\mathrm{E}$ has a salient antecedent $\mathrm{A}$ and, modulo $\exists$-type shifting, (a) A entails F-clo(E), and (b) E entails F-clo(A).

2 Romero (1998:31) asserts that natural semantics for else considers the implicit argument of else to be the F-marked constituent. 
In fact, the existence of "else" modification sheds light on the structure of sluicing. Merchant (2001:122) has observed that the modifier else following wh-words can occur in sluicing, but not in cleft-like pseudosluicing (Merchant 2001:122) as in (6).

(6) Harry was there, but I don't know who else (*it was).

Along this line, it seems that the prohibition of qita 'other' in (4) complies with the fact that Chinese sluicing is a cleft-like pseudosluicing analysis. In other words, sluice clause in Chinese is a simple clause, consisting of a subject pro (instead of explicit it in English), copula shi 'be', and $w h$-word without involving any movement as in (5) (Adams 2003, Adams and Tomioka 2012, Wei 2004, 2011, and Li and Wei 2014).

Reasonable as it seems, an empirical problem arises. Virtually, we find that the optional modifier qita in (4) does not play a role in expressing "else" modification in Chinese sluicing but the adverb hai 'still' and the verb you 'have' do. By attaching hai you 'still have' in front of the wh-phrase in (7), the equivalent meaning and function of "else" can be obtained. We believe that this effect is activated by hai 'still' in company with the verb you 'have', the so-called hai modification.

(7) Zhangsan hui lai, dan wo bu zhidao*(hai you) shei/(qita) shenme ren. Zhangsan will come but I not know still have who other what person 'Zhangsan will come, but I don't know who else will come (besides Zhangsan).'

The aim of this paper is to argue that (7) is a kind of you sluice in Chinese, whose existence does not jeopardize but instead supports the pseudosluicing analysis, on the basis of the fact that shi 'be' and you 'have' are parallel in their transitive and intransitive use (Huang 1988). This paper shows that you sluice can be naturally articulated under the simple sluice structure, [pro you wh-word]. In this structure, the subject pro can refer to a nominal antecedent or an event antecedent.

The organization of this paper is as follows. Section 2 introduces the properties of you sluice and the differences between you sluice and shi sluice. Section 3 focuses on how to interpret hai 'still' modification under pseudosluicing. Section 4 is a brief summary.

\section{You 'have' sluice}

Sluice involving you 'have' cannot take prepositional or adjunct $w$-elements such as weishenme 'why' as its complements. Such a restriction is closely related to the fact that there is a selectional restriction between you 'have' and the following wh-phrase. Based on this fact, we propose that [pro you whword] is the essential structure of you sluice in Chinese, lending support to the pseudosluicing analysis.

\subsection{Possessive and existential you sluice}

The properties of you sluice can be displayed from three respects: (i) the selectional restriction between you 'have' and the following wh-phrase, (ii) the interpretation of you, and (iii) parallelism. 
First, you sluice cannot co-occur with prepositional wh-adjuncts, such as weishenme 'why' and weileshenme 'for what purpose' as in (8a-b), but if the whadjuncts are replaced with nominal $w h$-words denoting the similar meanings, such as shenme-yuanyi/shenme-liyou 'what reason' and shenme-mudi 'what purpose', respectively, you sluice is allowed in (9). It reveals that there is a selectional restriction between you 'have' and the wh-phrase. Only nominal wh-words can appear after the verb.

(8) a. *Zhangsan bu neng lai, dan wo bu zhidao you weishenme.

Zhangsan not can come but I not know have why

'(lit.) Zhangsan cannot come, but I don't know why there is.'

b. *Zhangsan yiding yao lai, dan wo bu zhidao you weileshenme.

Zhangsan certainly will come but I not know have for.what.purpose

'(lit.) Zhangsan certainly will come, but I don't know what purpose there is.'

(9) a. Zhangsan bu neng lai, dan wo bu zhidao you shenme-yuanyin.

Zhangsan not can come but I not know have what-reason

'(lit.) Zhangsan cannot come, but I don't know what reason he has for his not coming.'

'(lit.) Zhangsan cannot come, but I don't know what reason there is for the fact that he cannot come.'

b. Zhangsan yiding yao lai, dan wo bu zhidao you shenme-mudi. Zhangsan certainly will come but I not know have what-purpose '(lit.) Zhangsan certainly will come, but I don't know what purpose Zhangsan has.' '(lit.) Zhangsan certainly will come, but I don't know what purpose there is for the fact that he certainly will come.'

Second, according to Huang (1987, 1988), the verb you 'have' has two sorts of use: transitive and intransitive use. The transitive you 'have' conveying possessive reading involves two arguments. The subject argument can be a possessor in (10a), denoting possessive reading, or location in (10b), denoting locational possessive reading. One of the characteristics of the possessive you 'have' is that it can take indefinite or definite object argument. ${ }^{3}$ As to the pure intransitive existential you, it only takes one indefinite argument as in (10c). ${ }^{4}$

3 Somewhat different from Huang's (1988) judgments, Tsai (2002) considers that the definite object in locative existential is not viable.

4 From the perspective of historical syntax, Tsai (2002) argued that you 'have' has undergone a process of semantic extension in the following sequence: possessive $>$ locative existential $>$ existential. In a sense, this order is in conformity with Huang's analysis on the verb you. In this squib, we will recognize location possessive in $(10 \mathrm{~b})$ as a structure being at a stage between pure possessive and pure existential constructions. 
(10) a. Ta you yi-ben shu/ zhe-ben shu. he has one-CL book this-CL book

(Possessive) 'He has a book/this book.'
b. Jiaoshi li you yi-ben classroom inside has one-CL book this-CL book '(lit.) In the classroom there is a book/the book.'
c. You yi-ben shu zai jiaoshi li.
EX one-CL book at classroom inside
(Existential)
'There is a book in the classroom.'

When you appears in sluice as in (9a), the sluice clause [you shenme-yuanyin] 'have what reason' ambiguously yields two meanings. One is 'what reason he (Zhangsan) has/owns for his not coming,' which indicates that you 'have' is a transitive verb with two arguments: the subject possessor ta 'he' and the whobject possessee shenme-yuanyin 'what reason'. The other meaning of (9a) is 'what reason there is for the fact that he (Zhangsan) cannot come.' Under this circumstance, the possessive you takes the situation that Zhangsan cannot come as an event subject and the wh-word shenme-yuanyin 'what reason' as the object. In other words, the situation may accommodate reasons for his absence, conveying a kind of existential reading, 'what reason there is for the fact that he cannot come'. In that sense, you 'have' here, also being a kind of possessive transitive verb, contains two arguments. The similar ambiguity also arises in (9b). ${ }^{5}$

One more fact of you in regards to the notion of parallelism is that you 'have' in the second conjunct cannot find its semantic or syntactic correlate in the first conjunct. It means that the verb you is independently present in the sluice clause and the clause where you appears is not derived from the deletion of a non-elliptical structure parallel to the antecedent clause (Fox and Lasnik 2003). This property of you is akin to that of the copula shi in Chinese sluicing in (5).

Based on the above three properties, the selectional restriction between you and $w h$-phrase, the transitive use of you, and non-parallel you, we will propose that you sluice is a variant of pseudosluicing, containing an implicit subject pro, the verb you, and wh-phrase, in the sluice clause, akin to shi 'be' sluice, [pro, $(s h i)$, wh-phrase] (Adams 2003, Wei 2004, 2011, Adams and Tomioka 2012, Li and Wei 2014). Before turning to the analysis of you sluice, let's see how shi sluice sheds light on the operation in you sluice.

5 Some native speakers accept (i) with aspectual marker zhe after you, supporting the possessive analysis (Huang 1988), whereas some don't. It indicates that the use of you in sluice is not stable when zhe appears.

(i) Zhangsan bu neng lai, dan wo bu zhidao you zhe shenme-yuanyin. Zhangsan not can come but I not know have ASP what-reason '(lit.) Zhangsan cannot come, but I don't know what reason he has had for his not coming.' '(lit.) Zhangsan cannot come, but I don't know what reason there has been for the fact that he cannot come.' 


\subsection{Shi sluice and pseudosluicing analysis}

The major difference between you sluice and shi sluice lies in the use of the adjunct $w h$-word. Wh-adjuncts such as weishenme 'why' and weileshenme 'for what purpose' are legitimate in shi sluice in (11), but not in you sluice in (8). We believe that the discrepancy lies in the different functions of you 'have' and shi 'be' in sluicing.

(11) Zhangsan bu neng lai, dan wo bu zhidao (shi) weishenme/weileshenme. Zhangsan not can come but I not know be why for.what.purpose 'Zhangsan cannot come, but I don't know why/for what purpose.'

According to Wei (2004, 2011), Adams and Tomioka (2012), Li and Wei (2014), the occurrence of shi 'be' depends on whether $w h$-phrase is predicative or not. ${ }^{6}$ When a $w h$-phrase is non-predicative, the copula verb is obligatory, whereas when a wh-phrase is predicative, shi 'be' becomes optional as an emphatic marker.' For example, the $w h$-phrase shei 'who' in (12a) is not a predicate; thus, the copular shi is obligatory. In contrast, since wh-adjunct weishenme 'why' in (12b) can be decomposed into a preposition wei 'for' and wh-word shenme 'what', the whadjunct is virtually a prepositional phrase, being eligible to be a predicate. In this case, the copular shi 'be', serving as an emphatic marker, is optional. The difference between (12b) and (12c) is that the wh-phrase shenme-yuanyin 'what reason' in (12c) is a nominal predicate, in which shenme 'what' morphologically

6 Wang (2002) and Wang and $\mathrm{Wu}$ (2006), extending the movement and deletion approach (Merchant 2001) to Chinese sluicing, argue that the wh-phrase is a focused constituent, which undergoes raising to the left periphery of the clause. Then IP-deletion applies, deriving a counterpart to English sluicing. Due to the limited space, we will not discuss the argument for pseudosluicing analysis and against the movement and deletion analysis. Readers can refer to Wei (2004, 2011), Li and Wei (2014), Adams (2003), Adams and Tomioka (2012), among others for more details.

7 The predication analysis of sluicing, proposed by Wei $(2004,2011)$ and also agreed by Adams and Tomioka (2012), argues that the non-predicative group includes only two wh-words: shei 'who' and shenme 'what', whereas the latter group extends to cover all other wh-elements in Mandarin. The predicative $w h$-words can be further classified into three types according to the type of predication: (i) the modificational type, in which predication is derived from a modifier-modifiee relation within the wh-phrase, e.g. [shenme [ren]] 'what person' and [shenme [dongxi]] 'what thing', (ii) the prepositional type, in which predication is mediated via a preposition, e.g. wei 'for' in weishenme 'for what', and (iii) the adjectival type, e.g. duo-gui 'how expensive', in which predication results directly from the adjective itself. The two simplex wh-words, shei 'who' and shenme 'what', do not fit into the three predicational patterns. That is the reason why the copular shi is obligatory. 
modifies the head noun yuanyin 'reason', ${ }^{8}$ in contrast to the prepositional predicate weishenme 'why' in (12b). Thus, all types of wh-phrase can be preceded by the verb $s h i .^{9,10}$ Next, let's see how pro gets interpreted.

(12)a. Zhangsan kanjian yi-ge ren, dan wo bu zhidao [pro*(shi) shei]. Zhangsan saw one-CL person but I not know be who

'Zhangsan saw someone, but I don't know who.'

b. Zhangsan bu neng lai, dan wo bu zhidao [pro (shi) weishenme]. Zhangsan not can come but I not know be why 'Zhangsan cannot come, but I don't know why.'

c. Zhangsan bu neng lai, dan wo bu zhidao [pro(shi) shenme-yuanyin]. Zhangsan not can come but I not know be what-reason 'Zhangsan cannot come, but I don't know what reasons.'

The pro subject, as claimed by Wei (2004, 2011), Adams (2003), and Adams and Tomioka (2012), is an event pro, assuming the semantic function of the wh-phrase via predication and further referring to the correlate of the same semantic function in the logical form. There is a discrepancy between event pro with overt antecedent and that with covert antecedent. The former refers to a realized content-laden object, while the latter refers to a presupposed/implied object. Put simply, the construal of the pro might be associated with a covert or overt thematic function of a specific predicate in LF, involving the notion of event as argument (Davidson 1967, Parsons 1990). On the one hand, the pro in (12a) can refer to the indefinite overt antecedent, yi-ge ren 'a person'; on the other, it also can refer to the definite description, the person that Zhangsan saw, in the sense of Evans' (1980) e-type pronoun. As to (12b, c), the pro is referential with the covert peripheral "reason" argument of the event that Zhangsan cannot come in line with Parsons' (1990) event structure.

\subsection{You sluice as a variant of pseudosluicing}

Under the pseudosluicing frame [pro, you, wh-phrase], we propose that the interpretation of pro is closely related to the possessive use of you.

8 The idea of modificational prediction relates to patterns found with nominal predicate constructions in Mandarin Chinese as in (1). Readers can refer to Wei (2004, 2007) and Zhang (2009) for more details.

(i) a. Zhangsan $[*($ Taiwan $)$ [ren]]

Zhangsan Taiwan people

'Zhangsan is a Taiwanese.'

b. Zhe haizi [*(da) [yanjing]].

this child big eye

'The child has big eyes.'

9 The only exception is zhemeyang 'how'. Owing to the limit of space, readers can refer to Li and Wei (2014) for more details.

10The division of shi in pseudosluicing complies with Huang's (1988) analysis on the transitive/ intransitive use of $s h i$ 'be'. The obligatory $s h i$ 'be' in front of wh-phrases shei 'who' and shenme 'what' is analogous to the transitive shi, a two-place predicate forming identificational or specificational copulative sentences. On the other hand, the optional $s h i$ 'be' preceding the other $w h$-phrases acts like an intransitive $s h i$ 'be', being a focus-oriented raising auxiliary in sluice. 
Let's turn to how (9), as repeated in (13), gets interpreted under pseudosluicing analysis. The possessive verb you 'have', a two-term predicate, requires a possessor to be its subject and a theme argument shenme yuanyin 'what reason' to be its object. In this case, the subject pro will refer to the animate Zhangsan in the first conjunct, who "owns" the reasons of not coming as a possessor. On the other hand, if the pro subject takes the correlative event occurring in the first conjunct as its referent, the structure with possessive you 'have', taking event pro as subject argument and shenme yuanyin 'what reason' as theme argument, denotes 'what reason there is for the fact that Zhangsan cannot come.' More specifically, the subject pro acts like an E-type pro (Evans 1980), referring to the previous event 'Zhangsan cannot come.'

(13) Zhangsan bu neng lai, dan wo bu zhidao [pro you shenme-yuanyin]. Zhangsan not can come but I not know have what-reason

'(lit.) Zhangsan cannot come, but I don't know what reason he has for his not coming.'

'(lit.) Zhangsan cannot come, but I don't know what reason there is for the fact that he cannot come.'

Summing up, we can say that the antecedents of pro can be a nominal or an event, each of which matches the possessive use of you in sluice clause. The question that follows is why wh-adjuncts such as weishenme 'why' and weileshenme 'for what purpose' in (8) cannot be used in you sluice, in contrast to the wh-nominals such as shenme-yuanyin 'what reason' and shenme-mudi 'what purpose' in (9). The answer lies in the argument structure of the verb you 'have', which requires a canonical nominal theme argument, rather than a peripheral adjunct argument. Thus, the proposed pseudosluicing analysis can naturally capture the grammatical contrast between (8) and (9), without resorting to any ad hoc stipulation.

One of the reviewers raises the question of why (14a) is unacceptable if the pro preceding you 'have' refers to the covert peripheral argument of the event, time or place, just like the pro preceding shi 'be' in (14b) in the pseudosluicing sentence.

(14) a. *Zhangsan lai le, dan wo bu zhidao [pro you shenme shijian/difang] Zhangsan come LE but I not know have what time place 'Zhangsan came, but I don't know what time/place exists for the time/place of the event.'

'Zhangsan came, but I don't know what time/place he had.'

b. Zhangsan lai le, dan wo bu zhidao [pro shi shenme shijian/difang] Zhangsan come LE but I not know be what time place

'Zhangsan came, but I don't know what time/place it was.'

We find that this puzzle is closely related to another difference between you sluice and shi sluice in particular on the condition that the $w h$-phrases are the socalled adjuncts or peripheral arguments of an event (Parsons 1990) and that the antecedent of pro is covert. When Wei $(2004,2011)$, Adams (2003), and Adams and Tomioka (2012) argues that the event pro in (14b) is referential with the covert 
peripheral argument (time or place) of the event, the sluice is interpreted as 'what time/place is the time/place of the event that Zhangsan came'. The shi focuses on the time/place of the event on both subject and predicate. In contrast, in you sluice in (14a), the interpretation of pro is ambiguous, as argued in this paper. On the one hand, it may refer to Zhangsan as a possessor and the entire sluice denotes 'what time/place did Zhangsan have'. On the other, the pro may refer to the event of Zhangsan's coming. In this case, the sluice denotes 'what time/place there is for the event that Zhangsan came.' However, these two interpretations are invalid, as shown in (14a). The oddity of (14a) is in contrast with the acceptability of (15), also a you sluice structure. When the event of Zhangsan's coming has not happened, the you sluice is acceptable, either when pro refers to Zhangsan as a possessor or when pro refers to the event.' The contrast between (14a) and (15) may lead us to a possible answer to the question of why (14a) is unacceptable. That is, since Zhangsan has already come to a certain place at a certain time, it is inappropriate to ask what place/time he has or what place/time exists for his coming. Therefore, the ungrammaticality of (14a) may be attributed to semantic conflict between the antecedent clause and sluice clause.

(15) Zhangsan dei/bixu lai, dan wo bu zhidao [pro you shenme shijian] Zhangsan has.to come but I not know have what time 'Zhangsan has to come, but I don't know what time exists for his coming.' 'Zhangsan has to come, but I don't know what time he has.'

\subsection{Some extensions of you sluice}

If you sluice with possessive reading is on the right track, we can apply this analysis to some relevant examples to see if this pseudosluicing-like account can explain some variants of you sluice, particularly those containing wh-phrases denoting quantity and degree.

The ambiguity in (16) can be explained by the construal of pro. When pro refers to the animate possessor matrix subject, $t a$ 'him' as in (16a), the entire sluice denotes the meaning, 'how many (cats) he owns.' On the other hand, when the antecedent of pro carries an E-type interpretation (Evans 1980) relating to the correlative event as in (16b), with a definite description 'the cats that he raises', the pro here is deemed as an E-type pronoun. The second conjunct means 'I don't know how many cats that he raises there are.'

(16) Ta yang mao, dan wo bu zhidao [pro you jizhi]. he raise cat but I not know have how.many

a. '(lit.) He raises cat, but I don't know how many cats he owns.'

b. '(lit.) He raises cat, but I don't know how many cats that he raises there are.'

Interestingly, sluicing with you 'have' can also precede adjectival $w h$-words as in (15). 
(17) Ta mai-le yi-dong fangzi, dan wo bu zhidao you duo gui he buy-LE one-CL house but I not know have how expensive '(lit.) He bought a house, but I don't know what degree of expensiveness there is for the house that he bought.'

Under the matrix [pro you wh-phrase], it is not feasible to co-index pro with the animate subject $t a$ 'him', because when it comes to the degree of expensiveness, the target of the degree should be an object, not a human being. Thus, the meaning of 'what degree of expensiveness he has' is in conflict with our world knowledge. We propose that the pro refers to an E-type definite description, 'the house he bought,' the entire sluice clause in (17) expresses the meaning of 'what degree of expensiveness there is for the house that he bought.'

To be brief, the construal of pro dominates the interpretation of you sluice structure. The pro in you sluice can refer to the animate subject, denoting possessor meaning or to an E-type reading, denoting existential reading. Without the verb you 'have', the sluice will be "automatically" interpreted as a pseudosluicing structure, in which the copula $s h i$ 'be' optionally appears between the subject pro and the whphrase. Below, we turn to hai 'still' modification in Chinese.

\section{Hai modification in pseudosluicing}

This section argues that the possessive use of you 'have' can function as "else" modification in English by attaching the adverb hai 'still' with you 'have' in the sluice clause, [pro hai you wh-phrase], as repeated below in (18).

Zhangsan hui lai, dan wo bu zhidao [hai you shei]

Zhangsan will come but I not know still have who

'Zhangsan will come, but I don't know who else will come (besides Zhangsan).'

In (18), the sluice clause, hai you shei 'who else', articulates the meaning: 'Besides Zhangsan, is there anyone else who will come?' We propose that there is a covert subject pro in front of hai you as in (19). Further, whenever hai you appears in the sluice clause, a function word chule 'besides' can optionally appear in front of the antecedent Zhangsan in the first conjunct as in (20). ${ }^{11}$ Further, chule 'besides' can cooccur with yiwai 'outside' in the final position of the first conjunct to form a circumphrase, denoting the meaning 'besides'. Note that the circum-phrase is not obligatory and can be naturally realized when hai you 'still have' appears in the sluice clause.

[pro hai you wh-phrase]

(20) (chule) Zhangsan hui lai (yiwai), wo bu zhidao [pro hai you shei]. besides Zhangsan will come outside I not know still have who 'Zhangsan will come; I don't know who else will come (besides Zhangsan).'

11 Here, chule 'besides' might be considered as a preposition taking a NP complement or a complementizer leading a clause. We leave this for further research. 
According to our previous analysis, the pro in (20) may refer to the animate matrix subject Zhangsan. If that is the case, the sluice clause conveys the meaning of Zhangsan hai you shei 'who does Zhangsan still has,' which is semantically anomalous. However, it is important to note that the antecedent of the pro should be restricted by the optional circum-phrase chule ... yiwei 'besides' in the antecedent clause. When chule ... yiwei 'besides' is imposed on the antecedent of pro, it means that the interpretation of the pro is also restricted by the circum-phrase.

More specifically, we propose that the pro in (20) refers to a set of persons besides Zhangsan, which can be literally articulated as chule Zhangsan yiwei (de ren) 'the set of persons besides Zhangsan.' It means that the pro is co-referential with a certain set, which is restricted by the circum-phrase chule ... yiwei 'besides' and which can be syntactically realized as a set of persons ren 'person' not including Zhangsan, a sort of nominal antecedent. In that sense, the entire sluice could be realized as [chule Zhangsan yiwei (de ren)] hai you shei 'who else there is besides Zhangsan.' The circum-phrase in the second conjunct chule ... yiwai is not overly present for two reasons. The subject pro, also being restricted by the circumphrase, is implicit, so the appearance of the circum-phrase is not required. Even so, the "else" modification does not disappear, because the restrictor hai is still actively imposed on the empty subject, deducing the meaning of [chule Zhangsan yiwei (de ren)] hai you shei 'who else there is besides Zhangsan,' which is semantically denoted as 'for which $x, x$ is/are a person/persons other than Zhangsan, and $x$ and Zhangsan will come'. ${ }^{12}$ This view may be supported by two extended uses of hai you sluices, which involve either nominal pro or event pro antecedents as well as implicit restrictors as follows. ${ }^{13}$

An example of nominal pro within hai you sluice supports the nominal pro analysis in (20). Given the pseudosluicing analysis, hai you sluice is argued to

12 Here, the function of hai in sluice is akin to that of than in English as in (i), restricting the argument Harry in the first conjunct. Thus, we call Zhangsan the restrictor of hai.

(i) She talked to Harry, but I don't know to who ELSE (than Harry). (Romero 1998:52)

In that sense, the operation of hai 'still' here conforms to Liu's (2000) claim that "Hai is associated with a higher value, and its occurrence in a sentence entails another proposition already in the context, the one associated with a lower value."

13 The two-tracked interpretation of pro in you sluice coincides with an extended use of you 'have' released in Tang (2016: 402-403). He argues that the attributive use of you 'have' can be taken as an extended use of possessive you 'have' in Mandarin Chinese. In particular, his examples (Tang 2016) clearly demonstrate that an event or a nominal can be the subject of the attributive use of you 'have', describing 'achieving a certain degree of duration of an event, of weight, of distance, etc.' as in (i).

(i) a. [ta zou-le] you san tian le. he leave-LE have three day LE 'He has left for three days.'

b. [zhe-tiao yu] you sigongjin. This-CL fish have four kilogram

'This fish weighs four kilograms.' 
have a base-generated [pro hai you wh-word] structure. In (21), the pro refers to the explicit nominal antecedent shizhengfu 'city government'. The sluice denotes 'how far the city government is from the location of the speaker (here).' On the surface, there seems to be no circum-phrase in the clause. In fact, we believe that the implicit circum-phrase, which works with the adverb hai 'still', plays a crucial role in interpreting pro.

$$
\begin{aligned}
& \text { wo yao qu shizhengfu, qing wen [pro hai you duo yuan]. } \\
& \text { I want go city.government please ask }
\end{aligned}
$$

'(lit.) I want to go to the city government; I would like to ask how far it is from here.'

We find that the subject pro in (21), which apparently refers to the nominal antecedent shizhengfu 'city government', should be translated as the distance between the location of the speaker and the city government. Meanwhile, despite the lack of the overt circum-phrase, the existence of the adverb hai 'still' in the second conjunct implies that before getting 'here', the speaker might have moved a certain distance, which is not included in the distance in question. We propose that the adverb hai 'still' in company with an implicit circum-phrase is imposed on the interpretation of the nominal pro. It is apparent that the sluice clause can be literally articulated as [shizhengfu hai you duo yuan] 'how far it is from here to the city government', which should be precisely translated as [cong zheli dao shizhengfu (de juli)] hai you duo yuan 'what the distance between the location of the speaker (here) and the city government is, not including the distance that the speaker might have moved'. In other words, the pro, which on the surface refers to shizhengfu 'city government', should be denoted as the implicit nominal antecedent juli 'distance' between the two points.

In addition to the evidence of nominal pro, we also find that of event pro in another extended use of hai you sluice. It shows that the two-tracked analysis of pro is plausible.

(22) ta kuai dao le, wo bu zhidao [pro hai you jige zhongtou]. he soon arrive LE I not know still have how.many hour

'(lit.) He will arrive soon; I don't know how many more hours (from now till his arrival).'

In (22), the subject pro refers to an event antecedent, ta kuai dao le 'he will arrive soon'. Though the circum-phrase chule ... yiwei 'besides' does not overtly exist, the adverb hai 'still' is imposed on the empty event pro subject, implying that his arrival may have been expected for some time. Thus, the entire sluice can be articulated as [ta kuai dao (de shijian)] hai you jige zhongtou 'how many more hours (from now) there are for the event of his arrival, not including the previous expecting time.'

Furthermore, chule ... yiwei 'besides' not only affects the interpretation of the subject, but it also affects the interpretation of the predicate or the object as in (23). 
(23) Zhangsan (chule) yang (*chule) mao (yiwai), wo bu zhidao Zhangsan besides raise besides cat outside I not know

a. [pro hai you (qita) shenme-dongwu]. still have other what-animal

'(lit.) Zhangsan raises cat, but I don't know what other animals Zhangsan has (besides cat).'

b. [pro hai zuo-le shenme].

still do-ASP what

'(lit.) Zhangsan raises cat, but I don’t know what else Zhangsan has done (besides raising cat).'

In (23), the effect of chule ... yiwei 'besides' can reach up to the immediate VP yang mao 'raise cat' or even the non-adjacent nominal mao 'cat'. In (23b), the whole VP is restricted by the circum-phrase, the empty subject pro refers to Zhangsan and the sluice clause articulates the meaning of 'still doing something else besides raising cat.' This paper is mainly concerned with (23a). The pro here is co-indexed with the subject Zhangsan and the optional restrictor chule ... yiwei has an effect on the object mao 'cat', yielding the meaning 'I don't know what animals (besides the cats that Zhangsan raises) he has' in the second conjunct. That is, you 'have' here expresses the possessive reading. Zhangsan is the possessor, whereas 'which animals (besides the cats that Zhangsan raises)' is the possessee.

In fact, you 'have' in (23) may also exhibit existential reading on condition that the pro refers to the cats that Zhangsan raises, a definite description denoting an E-type reading as in (24). In the first conjunct, chule ... yiwei 'besides' is imposed on the cats that Zhangsan raises; in the second conjunct, the sluice clause focuses on the set of animals besides the cats that Zhangsan raises. Thus, the second conjunct can be translated as 'what other animals there are besides the cats that Zhangsan raises,' in which you 'have' in (24) expresses existential reading. The pro is co-referential with mao 'cats', which denotes the E-type reading 'the cats that Zhangsan raises' and which is restricted by the covert/overt restrictor chule ...yiwei 'besides'. In other words, the pro is also restricted by the circumphrase. Meanwhile, after hai modification, the entire sluice is translated as [chule (Zhangsan yang de) mao yiwei (de dongwu)] hai you (qita) shenme-dongwu "what other animals there are besides the cats that Zhangsan raises.' The construal of pro is affected by hai modification in sluice clause, parallel to English else modification on the objects cat and Mary in (25).

(24) Zhangsan (chule) yang (*chule) mao (yiwai), wo bu zhidao Zhangsan besides raise besides cat outside I not know [pro hai you (qita) shenme-dongwu]. still have other what-animal

'(lit.) Zhangsan raises cat, but I don't know what other animals there are (besides the cats that Zhangsan raises).' 
(25) a. John raises cat, but I don't know what other animals.

b. John saw Mary, but I don't know who else.

Similar phenomenon can be identified in (26) and (27), both of which wh-phrases inquire reason and time, respectively. In (26), the verb you 'have' carries possessive meaning.

(26) Zhangsan shuo ta (chule) ganmao bu neng lai (yiwei), wo bu zhidao Zhangsan say he besides get.cold not can come outside I not know [pro hai you (qita) shenme-liyou].

still have other what-reason

a. '(lit.) Zhangsan says he can't come because of the flu, but I don't know what other reasons he has (for his not coming) (besides catching cold).'

b. '(lit.) Zhangsan says he can't come because of the flu, but I don't know what other reasons there are (for his not coming) (besides catching cold).'

To derive the meaning of (26a), the pro has to refer to the matrix animate subject Zhangsan, the possessor; thus the verb you 'have' denotes the possessive reading. The sluice clause denotes 'what other reasons (besides catching cold) Zhangsan has,' in which the wh-word (qita) shenme-liyou 'what other reasons (besides catching flu)' is the possessee. That is, the optional circum-phrase chule ... yiwei 'besides' restricts the reason ganmao 'catching cold' rather than Zhangsan or ta 'he'. As to (26b), the pro is an E-type pro because it refers to the event 'Zhangsan cannot come'. The optional restrictor chule ... yiwei is imposed on the very reason of getting cold and the $w h$-word queries the existence of other reasons besides the reason of getting cold. In the meantime, after hai modification, the entire sluice clause denotes the meaning of "what other reasons (besides catching cold) there are for his not coming.'

The sentence (27) manifests similar interpretations in regards to the possessive reading. The sluice clause contains a nominal wh-word shenme-shijian 'what time'. The optional circum-phrase precedes what it confines, xingqisi 'Thursday' in the first conjunct. Accordingly, (27a) articulates the possessive reading with the pro referring to the subject $t a$ 'he', the possessor; the possessee is 'what other leisure time besides Thursday'. The entire sluice conveys the meaning of 'what other leisure time he has besides Thursday.' Moreover, (27b) carries a reading with the subject pro referring to a nominal antecedent, the set of days besides Thursday, [(chule) xingqisi ... (yiwai) de shijian] 'the days besides Thursday'. The entire sluice can be recovered as [chule xingqisi yiwei (de shijian)] hai you (qita) shenmeshijian 'what other leisure there is besides Thursday.'

(27) Ta (chule) xingqisi you kong (yiwai), wo bu zhidao

he besides Thursday have free outside I not know

[pro hai you (qita) shenme-shijian]. still have other what time 
a. '(lit.) He is free on Thursday, and I don't know what other leisure time he has besides Thursday.'

b. '(lit.) He is free on Thursday, and I don't know what other leisure time there is besides Thursday.'

\section{Conclusion}

This paper concludes that you sluice belongs to the pseudosluicing family, akin to shi sluice in Chinese. We have demonstrated that you sluice can be naturally articulated under the base-generated clause structure, [pro you wh-word], with pro either referring to a nominal antecedent or an event antecedent and you 'have' denoting possessive or existential reading as well as the extended attributive uses. Furthermore, this analysis successfully captures the collaboration of the circumphrase chule ... yiwei 'besides' with the hai modification in Chinese you sluice, opening a way to a better understanding of else modification in sluicing structures.

\section{Acknowledgments}

I would like to express my gratitude to the two reviewers for kindly giving me precious opportunities and insightful suggestions to improve this paper in a more comprehensive way. Thanks are also due to Audrey Li, Dylan Tsai, Jo-Wang Lin, Luther Liu, and Jonah Lin for their valuable opinions and discussions. Research for this paper was supported by grants from the Ministry of Science and Technology in Taiwan (MOST 103-2410-H-017-006, 104-2410-H-017-014, 105-2410-H-017029). The author is responsible for all errors that remain.

\section{References}

Adams, Perng Wang. 2003. The structure of sluicing in Mandarin Chinese. Proceedings of Pennsylvania Linguistics Colloquium 27, 1-16.

Adams, Perng Wang \& Satoshi Tomioka. 2012. Sluicing in Mandarin Chinese: An instance of pseudosluicing. In Jason Merchant \& Andrew Simpson (eds.), Sluicing: Cross-linguistic perspectives, 219-247. New York: Oxford University Press.

Davidson, Donald. 1967. The logical form of action sentences. In Nicholas Rescher (ed.), The logical of decision and action. Pittsburgh: University of Pittsburgh Press.

Evans, Gareth. 1980. Pronouns. Linguistic Inquiry 11. 337-362.

Fox, Danny \& Howard Lasnik. 2003. Successive-cyclic movement and island repair: The difference between sluicing and VP-ellipsis. Linguistic Inquiry 34. 143-154.

Huang, C.-T. James. 1987. Existential sentences in Chinese and (in)definiteness. In Eric Reuland \& Alice ter Meulen (eds.), The representation of (in)definiteness, 226-253. Cambridge, MA: MIT Press.

Huang, C.-T. James. 1988. Shuo 'shi' he 'you' [On 'be' and 'have' in Chinese]. The Bulletin of the Institute of History and Philology, Academia Sinica 59(1). 43-64.

Li, Y.-H. Audrey \& Ting-Chi Wei. 2014. Ellipsis. In C.-T. James Huang, Y.-H. Audrey 
Li \& Andrew Simpson (eds.), The handbook of Chinese linguistics, 275-310. New York: John Wiley \& Sons.

Liu, Feng-Hsi. 2000. The scalar particle hai in Chinese. Cahiers de LinguistiqueAsie Orientale 29(1). 41-84.

Merchant, Jason. 2001. The syntax of silence. Oxford: Oxford University Press.

Parsons, Terence. 1990. Events in the semantics of English: A study in subatomic semantics. Cambridge, MA: MIT Press.

Romero, Maribel. 1998. Focus and reconstruction effects in wh-phrases. University of Massachusetts Amherst $\mathrm{PhD}$ dissertation.

Tang, Ting-Chi. 2016. Huayu-de "zai zi ju” yu "you zi ju” [Zai 'at' structure and you 'have' structure in Chinese]. In Huayu yuyan fenxi rumen [An introduction to linguistic analysis of Chinese]. Taipei: Zhiliang Publishing Company.

Tsai, Wei-Tien Dylan. 2002. You 'have' in Taiwan Mandarin and dialects-On the social and historical aspects of grammatical theories (In Chinese). Tsing Hua Journal of Chinese Studies 32(2). 495-528.

Wang, Chyan-an. 2002. On sluicing in Mandarin Chinese. Taiwan: Tsing Hua University MA thesis.

Wang, C.-A. \& Wu, H.-H. 2006. Sluicing and focus movement in wh-in-situ languages. Penn Working Papers in Linguistics 12. 375-87. In Aviad Eillam, Tatjana Scheffler \& Joshua Tauberer (eds.), Proceedings of the 29th Annual Penn Linguistics Colloquium.

Wei, Ting-Chi. 2004. Predication and sluicing in Mandarin Chinese. Taiwan: National Kaohsiung Normal University PhD dissertation.

Wei, Ting-Chi. 2007. Nominal predicates in Mandarin Chinese. Taiwan Journal of Linguistics 5(2). 85-130.

Wei, Ting-Chi. 2011. Island repair effects of the left branch condition in Mandarin Chinese. Journal of East Asian Linguistics 20(3). 255-289.

Zhang, Quingwen. 2009. On the syntax of non-verbal predication in Mandarin Chinese. Hong Kong: Hong Kong Polytechnic University PhD dissertation.

Mailing Address: No. 116, Ho-Ping first Road, Graduate Institute of Taiwan History, Culture and Languages, National Kaohsiung Normal University, Kaohsiung 80201, Taiwan

Email: $\quad$ tingchiwei@nknu.edu.tw

Received: $\quad$ April 11, 2016

Accepted: $\quad$ March 13, 2017 


\title{
漢語帶“有”的切割結構與“還”的修飾
}

\author{
魏廷冀 \\ 國立高雄師範大學
}

\section{提要}

本文論證漢語帶 “有” 的切割結構為一種由基底衍生的準切割結構, 是由主語 pro、 動詞 “有” 以及疑問詞所組成的簡單句, 類似帶 “是” 的準切割句, 此兩種準切割 句之衍生與移位刪略無關。此準切割句中的主語 pro, 可指涉一個名詞前行語或事 件前行語; 至於 “有” 則表達一種所有義或存在義, 亦可用於描述屬性。此分析顯示, 漢語帶 “有” 的準切割句, 其限制詞 “除了……以外” 以及副詞 “還” 在語意及句 法介面上相互作用, 產生類似以移位刪略為主的英語切割句中 else 之修飾用法。

\section{關鍵詞}

還、else、所有義、存在義、切割結構、準切割結構 